\title{
RNA Polymerase Activity Assay on Biochips: Correlation between Template DNA Density and RNA Synthesis
}

\author{
Bokhui Lee, ${ }^{\dagger, a}$ Hyunjung Seo, ${ }^{\dagger, a}$ Sohyun Kim, ${ }^{\dagger}$ Woong Jung, ${ }^{\S}$ Dong woon Kim,,${ }^{\#}$ Woon-Seok Yeo, ${ }^{\dagger, *}$ and Dong-Eun Kim ${ }^{\dagger,+, *}$ \\ ${ }^{\dagger}$ Department of Bioscience and Biotechnology, ${ }^{\star}$ WCU program, Konkuk University, Seoul 143-701, Korea \\ *E-mail:kimde@konkuk.ac.kr(D.-E.Kim),wsyeo@konkuk.ac.kr(W.-S.Yeo) \\ ${ }^{\S}$ Department of Emergency Medicine, East-West Neo Medical Center, Kyung Hee University, Seoul 134-727, Korea \\ ${ }^{\#}$ Swine Science Division, National Institute of Animal Science, RDA, Cheonan 330-801, Korea \\ Received May 18, 2010, Accepted May 31, 2010
}

Key Words: Biochip, DNA density, MALDI-TOF MS, Monolayer, RNA polymerase

In vitro synthesis of RNAs by bacteriophage T7 RNA polymerase (T7 RNAP) has been applied extensively to the investigation of RNA serving as a biologically active molecule. T7 RNAP is a single subunit enzyme with a molecular weight of $98 \mathrm{kDa}$ that is capable of catalyzing transcription without any accessory proteins. ${ }^{1-3}$ Other RNA polymerases derived from bacteriophage (SP6 and T3) were also useful for in vitro synthesis of RNA. Each RNA polymerase has different DNA promoter sequences for initiation of transcription. The behavior of T7 RNAP is critically dependent on its interaction with the promoter element in template DNA. The T7 bacteriophage genome contains a variety of promoters that are recognized by T7 RNAP, all of which are related to a 23-base pair consensus sequence (see Figure 1). ${ }^{1}$ The promoter can be divided into a recognition domain, encompassing positions 17 through 5, and an initiation domain, encompassing positions 4 through +6 with a transcription start site initiates at the +1 position. ${ }^{4,5}$

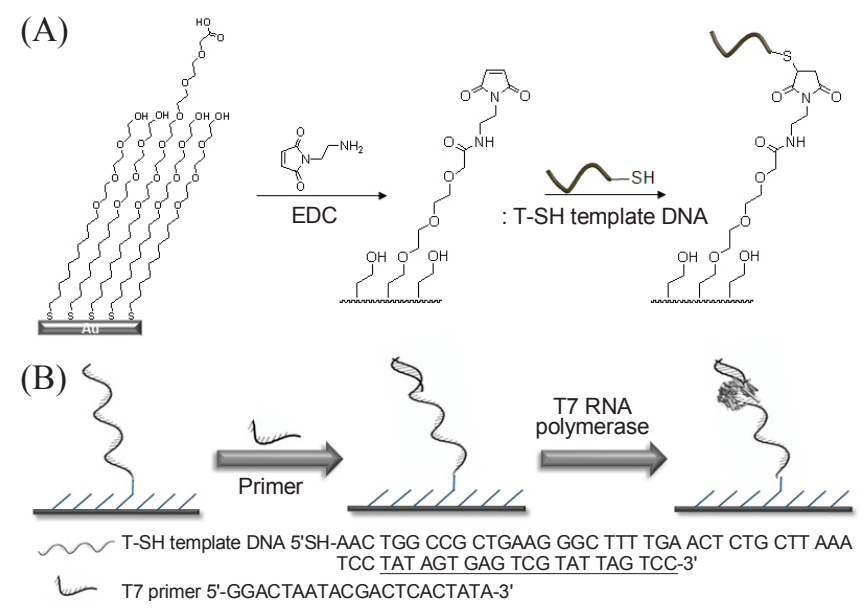

Figure 1. (A) Structure of SAMs on gold and chemical modifications to prepare template DNA-presenting biochips. The carboxylic acidpresenting monolayer was treated with 1-ethyl-3-(3-dimethylaminopropyl)carbodiimide hydrochloride (EDC) and $N$-aminoethyl maleimide, followed by thiolated template DNA. (B) Strategy for T7 RNAP activity assay on biochips and the sequences of oligonucleotides (T7 promoter sequences underlined) used in this study.

${ }^{\mathrm{a}}$ These authors equally contributed to this study.
Cell-free transcription and translation system on solid surface has been developed and utilized in many genomic studies. ${ }^{6-8}$ As a new research tool, cell-free gene expression has been applied to DNA-based biochips, which showed possibilities of developing synthetic biological systems and biochemical materials at nanoscale. ${ }^{8-11}$ The biosynthetic reaction on surface of microchips was first realized by Buxboim et al. and they developed and utilized the microchips assembled by photolithographic approach on silicon dioxide $\left(\mathrm{SiO}_{2}\right)$ for controlling the cell-free expression. ${ }^{7,8,12}$ This approach allows us to control the immobilized DNA and regulate the biosynthetic reactions in a more controlled manner. ${ }^{7}$ Recently, it has been reported that there exists attenuation of protein synthesis in a translation coupled with a transcription system on DNA-grafted biochips, which is likely due to molecular crowding caused by the translational machinery. $^{7}$

Here, we investigated T7 RNAP enzyme activity of RNA synthesis on self assembled monolayers (SAMs) on gold surface which presents template DNA at various surface densities ranging from $5 \%$ to $50 \%$. Using the matrix-assisted laser desorption/ionization-time of flight mass spectrometry (MALDITOF MS), binding of T7 RNAP to T7 promoter sequence in the DNA template on chip was analyzed and the activity of T7 RNAP to synthesize RNA on chip was assayed by monitoring the amount of RNA produced with polyacrylamide gel electrophoresis (PAGE). We observed that RNA synthesis is significantly affected by surface density of template DNA on the biochip.

Figure 1 illustrates the structure of monolayers used in this study, chemical modifications for preparation of a template DNA-presenting chip, and strategy for T7 RNAP activity assays on this chip. Carboxylic acid-presenting monolayers are converted to maleimide functionality - a thiol specific reactive group - by amide coupling reactions and subsequently thiolated template DNA is immobilized to the monolayer (Figure 1A). The template DNA-presenting monolayer is then annealed with DNA primer that constitutes intact $\mathrm{T} 7$ promoter sequence and subjected to the in vitro transcription reaction with T7 RNAP (Figure 1B).

First, we verified the chemical modifications on the surface shown in Figure 1A using MALDI-TOF MS. The acid-presenting monolayer was prepared from a mixed solution of tri(ethyl- 
(A)

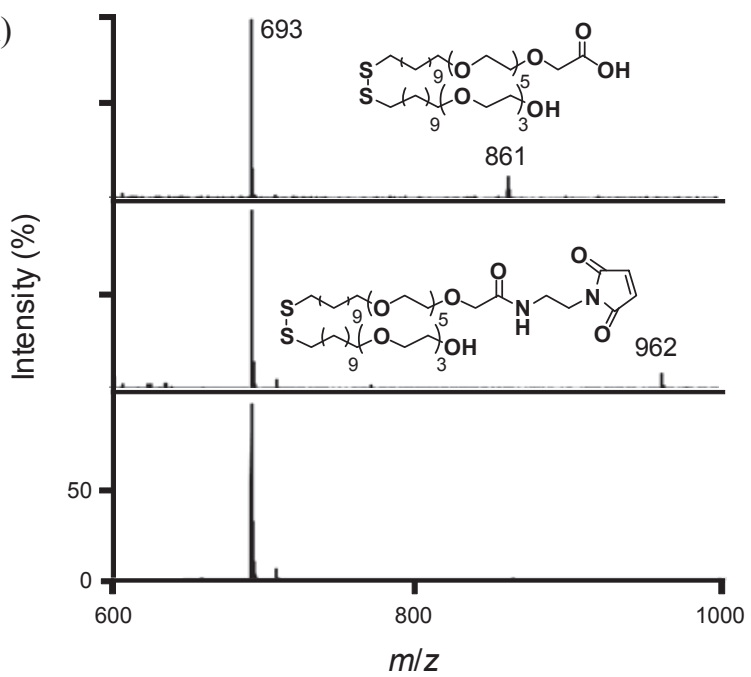

(B)

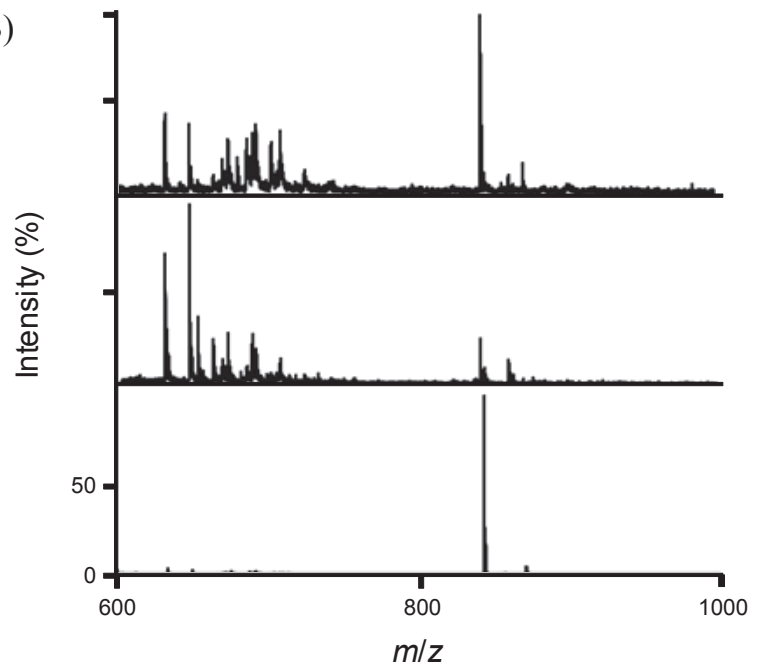

Figure 2. (A) Verification of chemical modifications on the monolayer by MALDI-TOF MS; carboxylic acid-presenting monolayer (top), after maleimide immobilization (middle), and after thiolated template DNA conjugation (bottom). (B) Verification of the presence of T7 RNAP on the monolayer by MALDI-TOF MS; the digested peptide fragments of T7 RNAP immobilized on the monolayer (top), in-solution (middle), and on the monolayer without primer treatment (bottom). For details, see the main text.

ene glycol)-terminated alkanethiol and acid group-terminated alkanethiol in a ratio of $9: 1$. The mass analysis gave two major peaks at $m / z 693[\mathrm{M}+\mathrm{Na}]^{+}$and $m / z 861[\mathrm{M}-\mathrm{H}+2 \mathrm{Na}]^{+}$ corresponding to tri(ethylene glycol)-terminated disulfide and mixed disulfide of acid and tri(ethylene glycol)-terminated alkanethiolates, respectively (Figure 2A, top). This monolayer was then treated with 1-ethyl-3-(3-dimethylaminopropyl)carbodiimide hydrochloride (EDC) $(100 \mathrm{mM}$ in PBS pH 7.4) and maleimide amine ( $50 \mathrm{mM}$ in PBS $\mathrm{pH} 7.4$ ) for $2 \mathrm{~h}$, and analyzed by MS. The peak at $m / z 861$ was absent and gave rise to a peak at $m / z 962[\mathrm{M}+\mathrm{Na}]^{+}$which corresponds to maleimide containing disulfide (Figure 2A, middle). The resulting maleimide presenting monolayer was then treated with thiolated template DNA ( $1 \mu \mathrm{M}$ in PBS). The mass spectrum of this monolayer showed that the peak at $\mathrm{m} / \mathrm{z} 962$ disappeared indicating the full

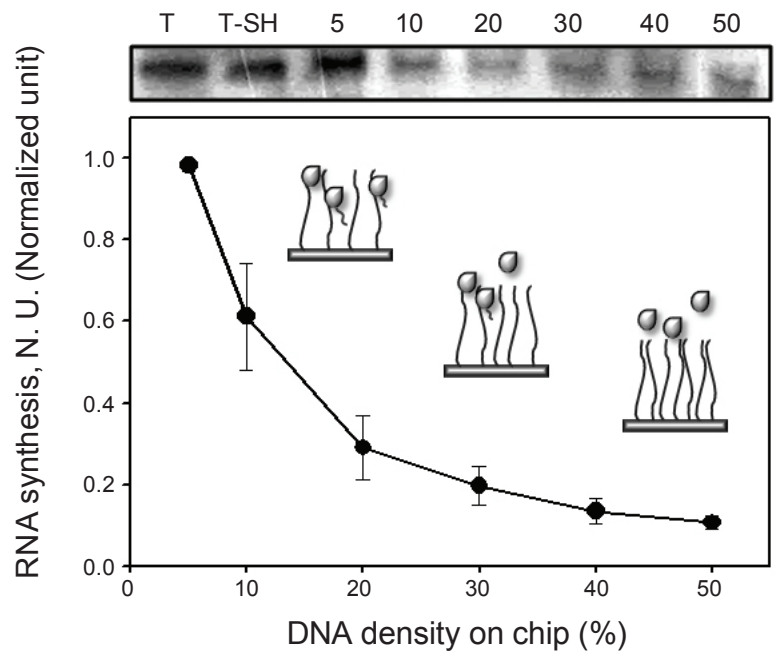

Figure 3. Measurement of RNA synthesis on chip. In vitro transcription was performed on DNA chips with increasing density of template DNA $(5,10,20,30,40$, and $50 \%)$ on surface of the chips, and the RNA products were analyzed by $10 \%$ urea-PAGE (top figure). Relative amount of synthesized RNA was obtained by dividing amount of RNA synthesized with each chip weight times DNA density. As a positive control, T and T-SH template DNA were also included for in vitro transcription reaction, which was performed in a solution.

conjugation of thiolated DNA to maleimide groups (Figure 2A, bottom). These results indicate that all chemical reactions proceeded as described in Figure 1A with high yield. Note that the direct observation of immobilized oligonucleotides on SAMs using MALDI-TOF MS has not been successful and has not been reported yet. Next, we tested the capability of T7 RNAP to recognize T7 promoter sequence on the monolayer. The template DNA-presenting monolayer was annealed with $8 \mu \mathrm{M}$ of primers and T7 RNAP in reaction buffer $(1.76 \mu \mathrm{M})$ was then applied to the monolayer. After incubation for $30 \mathrm{~min}$, the monolayer was treated with trypsin for $3 \mathrm{~h}$ at $37^{\circ} \mathrm{C}$, dried, and directly analyzed by MALDI-TOF MS. The mass spectrum showed several peptide fragment peaks from T7 RNAP, which well concurred with the spectrum obtained from in-solution digestion (Figure 2B, top and middle). As a control, we carried out same experiment except primer annealing step, which afforded the spectrum showing only trypsin auto-digestion peaks and trace of T7 RNAP digests. This result clearly indicates that T7 RNAP was specifically bound to T7 promoter sequence on the monolayer and then performed enzyme activity of RNA synthesis.

We next carried out the RNA synthesis reaction on the chip harboring the template DNA annealed with DNA primer that constitutes intact $\mathrm{T} 7$ promoter sequence. The DNA-grafted chips with various surface densities ranging from $5 \%$ to $50 \%$ were prepared and subjected to the in vitro transcription reaction with T7 RNAP. RNA synthesis was expected in the reaction on a surface of the chip DNA, and the reaction was repeated for several chips with increasing density of DNA grafted on the surface. As the density of DNA conjugated on the chip surface increased, amount of RNA synthesized per unit amount of template DNA decreased (Figure 3). In contrast to the result on the chip surface, RNA synthesis in a solution was 
not hampered with the same DNA template used in the chip assay regardless of thiol modification at the 5 ' end. This result indicates that T7 RNAP is the sensor of the DNA strand on the surface and is impeded in penetration into the DNA strand at high densities. This result is different from the earlier observation by Buxboim et al., in which RNA synthesis was not affected by the density of DNA on the chip. ${ }^{7}$ These discrepancies might be resulted from different densities and/or length of template DNA on the chip surface. Attenuation of RNA synthesis at dense DNA packing is likely due to molecular crowding that causes incorrect binding of the polymerase to the promoter sequence and impediment of RNA polymerase in translocation along the DNA template (possible configurations in Figure 3). As the template DNAs are placed in a less dense surface, they are likely to be more accessible to the transcription machinery than in the densely packed DNA on the surface.

In conclusion, RNA polymerase activity was successfully monitored on template DNA-presenting chips. The surface density of template DNA was closely related to the enzyme activity, which can be attributed to molecular crowding at the surface. This result will be applicable to design gene immobilized solid supports for synthetic biological systems on surface, which is different from solution reaction.

\section{Experimental Section}

Preparation of template DNA and primer. Template DNA (5'-AACTGGCCGCTGAAGGGCTTTTGAACTCTGCTT AAATCCTATAGTGAGTCGTATTAGTCC-3'; T7 promoter sequence underlined) and corresponding primer (5'-GGAC TAATACGACTCACTATA-3') were chemically synthesized (CosmoGentech, Seoul, Korea) and template DNA was modified with thiol at $5^{\prime}$ end of the sequences (T-SH) (BIONICS, Seoul, Korea).

Preparation of template DNA-presenting monolayers. The acid-presenting monolayers were prepared from a mixed solution of tri(ethylene glycol)-terminated alkanethiol and acid group-terminated alkanethiol in ethanol for $12 \mathrm{~h}$ (the total concentration of thiol was $1 \mathrm{mM})$. Acid-presenting monolayers were treated with EDC (100 mM in PBS pH 7.4) and maleimide amine (50 mM in PBS pH 7.4) for $2 \mathrm{~h}$, and washed with distilled water. The resulting maleimide-presenting monolayers were then treated with thiolated template DNA $(1 \mu \mathrm{M}$ in PBS).

On-chip tryptic digestion of immobilized T7 RNA polymerase. The template DNA-presenting monolayers were annealed with $8 \mu \mathrm{M}$ of primers at $65^{\circ} \mathrm{C}$ for $5 \mathrm{~min}$, at $25^{\circ} \mathrm{C}$ for $20 \mathrm{~min}$, and stored at $4{ }^{\circ} \mathrm{C}$ until use. T7 RNAP in reaction buffer $(1.76$ $\mu \mathrm{M}$ in $40 \mathrm{mM}$ Tris- $\mathrm{HCl}, 15 \mathrm{mM} \mathrm{MgCl}_{2}$ ) was then applied to the monolayers, which were incubated for $30 \mathrm{~min}$ and briefly rinsed with distilled water. Trypsin $(10 \mathrm{ng} / \mathrm{L}$ in $20 \mathrm{mM}$ ammonium bicarbonate, $0.5 \mathrm{mM}$ calcium chloride, $10 \%$ acetonitrile) was treated on these monolayers for $3 \mathrm{~h}$ at $37{ }^{\circ} \mathrm{C}$. The monolayers were dried and directly analyzed by MALDI-TOF MS.

Mass analysis. Mass analysis was performed using an Autoflex III MALDI-TOF mass spectrometer (Bruker Daltonics) equipped with a smartbeam laser as an ionization source. All of the spectra were acquired with $19 \mathrm{kV}$ accelerating voltage, a $50 \mathrm{~Hz}$ repetition rate, and positive mode with the average of $\sim 500$ shots. To confirm the reaction progression, monolayers were analyzed with 2,5-dihydroxybenzoic acid (DHB, $5 \mathrm{mg} / \mathrm{mL}$ in acetonitrile) as a matrix. Tryptic peptides of T7 RNAP were analyzed with a-cyano-4-hydroxycinnamic acid $(1 \mathrm{mg} / 150 \mu \mathrm{L}$ in $50 \%$ acetonitrile, $0.05 \%$ TFA) as a matrix.

In vitro transcription on a chip. The template DNA presenting chips were immersed in $100 \mu \mathrm{L}$ of distilled water containing $8 \mu \mathrm{M}$ primers which were annealed by heating at $95{ }^{\circ} \mathrm{C}$ for 5 min and cooling at $25{ }^{\circ} \mathrm{C}$ for $20 \mathrm{~min}$. The chips harboring primer annealed template DNA were stored at $4{ }^{\circ} \mathrm{C}$ prior to use. In vitro transcription reaction was performed by dropping $30 \mu \mathrm{L}$ of the reaction mixture containing $1.76 \mu \mathrm{M}$ T7 RNAP and $2 \mathrm{mM}$ NTPs (ATP, GTP, CTP, and UTP) in the reaction buffer (40 mM Tris- $\mathrm{HCl}, 15 \mathrm{mM} \mathrm{MgCl}_{2}, 2 \mathrm{mM}$ spermidine, $10 \mathrm{mM}$ DTT) to the chips annealed with primer. The chips were incubated at $37^{\circ} \mathrm{C}$ for $3 \mathrm{~h}$ and the RNA products were resolved by denaturing polyacrylamide gel electrophoresis (10\% ureaPAGE) and detected by ethidium bromide staining. Amount of RNA synthesized in the reaction was quantified by measuring the RNA band intensity using the Gel-Pro analyzer software (Media Cybernetics, Bethesda, USA) and the chips were weighed for assessing the surface area.

RNA synthesis in solution. Each of the $4 \mu \mathrm{M}$ T and T-SH template DNA was annealed with $8 \mu \mathrm{M}$ primer by heating $95^{\circ} \mathrm{C}$ for $5 \mathrm{~min}$ and $42{ }^{\circ} \mathrm{C}$ for $10 \mathrm{~min}$, and cooling at $25^{\circ} \mathrm{C}$ for $10 \mathrm{~min}$. In vitro transcription reaction $(30 \mu \mathrm{L})$ was performed by mixing the T7 RNAP with the reaction buffer as described above.

Acknowledgments. This research was supported by Basic Science Research Program through the National Research Foundation of Korea (NRF) funded by the Ministry of Education, Science and Technology (grant 2009-0064280) and by the Korea Research Foundation Grant funded by the Korean Government (MOEHRD) (KRF-2008-314-C00240), and by a grant from the Biogreen 21 Program and Agenda program (NIAS, 8-20-52), Rural Development Administration, Republic of Korea.

\section{References}

1. Dunn, J. J.; Studier, F. W. J. Mol. Biol. 1983, 166, 477.

2. Temiakov, D.; Anikin, M.; McAllister, W. T. J. Biol. Chem. 2002, $277,47035$.

3. Jia, Y.; Patel, S. S. J. Biol. Chem. 1997, 272, 30147.

4. Chapman, K. A.; Burgess, R. R. Nucleic Acids Res. 1987, 15, 5413.

5. Chapman, K. A.; Gunderson, S. I.; Anello, M.; Wells, R. D.; Burgess, R. R. Nucleic Acids Res. 1988, 16, 4511.

6. Angenendt, P.; Nyarsik, L.; Szaflarski, W.; Glokler, J.; Nierhaus, K. H.; Lehrach, H.; Cahill, D. J.; Lueking, A. Anal. Chem. 2004, $76,1844$.

7. Buxboim, A.; Daube, S. S.; Bar-Ziv, R. Mol. Syst. Biol. 2008, 4, 181 .

8. Buxboim, A.; Daube, S. S.; Bar-Ziv, R. Nano Lett. 2009, 9, 909.

9. Doktycz, M. J.; Simpson, M. L. Mol. Syst. Biol. 2007, 3, 125.

10. Jungmann, R.; Renner, S.; Simmel, F. C. Hfsp J. 2008, 2, 99.

11. Choi, J. W.; Oh, B. K.; Kim, Y. K.; Min, J. J. Microbiol. Biotechnol. 2007, 17, 5 .

12. Buxboim, A.; Bar-Dagan, M.; Frydman, V.; Zbaida, D.; Morpurgo, M.; Bar-Ziv, R. Small 2007, 3, 500. 